\title{
University Students' Preferences of Reading from a Printed Paper or a Digital Screen - A Longitudinal Study
}

\author{
Zekeriya Kazanci
}

\begin{abstract}
Reading mediums have reached a wider range of facilities in the last couple of decades whereas paper has been almost the only choice for a long time. Academically, with the development of electronic learning approaches, students are involved in reading from a digital screen much more than before. The huge corpus of instruction which flows through digital screens arises some questions on students' preferences and comfort about reading from a digital screen instead of reading from conventional printed papers. The aim of this study is to investigate the preferences of university students for reading from a printed text or from a digital screen in 2008 and 2014 and also to reveal if this preference changes depending on their gender or department. A questionnaire was conducted to 792 students from eight different departments of the faculty of education. Results indicate that, the majority of the students still prefer traditional printed paper instead of digital screen for their reading activities and this preference of them have not changed in 6 years. Furthermore, whereas gender does not play an effective role in this preference, the students' department may affect their choice.
\end{abstract}

Index Terms-Digital screen, printed paper, reading preferences, students' preferences.

\section{INTRODUCTION}

Digital devices and the Internet which are more integrated in our daily lives now, provide several reading facilities which are faster, cheaper, and more ubiquitous than ever. Almost all reading materials, which used to be on the paper before, have digital versions now. The most common reading mediums such as newspapers, magazines, novels, and course books now have their digital versions which allow carrying literally thousands of them in one small tablet PC or even in a smartphone. Educational technologies and materials are also affected by this widespread phenomenon. Now tablet PCs and similar devices are being used almost all stages of education from kindergarten to university. Conventional blackboard and chalk materials have already been replaced by projectors and smart boards. This means learners are subjected to the digital screens more than ever. The new learning mediums have led many researchers to investigate the effects, the perception, and the preferences of these new reading environments which mostly include digital screens of various devices. Many studies concentrate on the comparison of digital screens with their predecessor, conventional printed paper, from various aspects.

Some studies focused on more physical aspect of reading from a computer screen. Kurniawan and Zaphiris [1]

Manuscript received April 12, 2015; revised June 15, 2015.

Zekeriya Kazanci is with the Çukurova University, Turkey (e-mail: zkazanci@cu.edu.tr). conducted an experimental research to compare the reading speeds of reading from paper or screen and they concluded that reading from screen is slower $(10-30 \%)$ than reading from paper. This finding may have some implications for the designers of electronic reading materials since the reading speed may affect the preferences and the perceptions of readers. Therefore many researchers are interested in the preferences of readers as well.

Auman [2] studied high school students to investigate their preferences to read from the screen or paper and what makes their decisions. She also had an experimental part of her study to investigate if there is a difference in the comprehension of the students. Although students prefer reading from a screen, the comprehension score of the paper group is higher than the screen group. It may be thought that the results show the ambition of teenagers to use computer. Comprehension has been significant aspect of comparison of reading from paper or digital screen. In order to study this aspect, Wangen, Walgermo and Brønnick [3] divided tenth grade students into two groups of which have given the same text yet one group on screen and the other on the paper. Then they were given a comprehension text and their test scores were evaluated in order to compare the difference. Their findings show that students who read texts in print scored significantly better on the reading comprehension test than students who read the texts digitally. Ackerman and Lauterman [4] studied the exams that are taken on screen or on paper in order to find out if there is a difference. The students taking their exams on paper had better scores than on screen ones. They have commented that as "...technology-related barriers should have taken their effect..."

Studies on older/higher education groups also investigate the preferences of learners for their reading media. Spencer [5] studied the preferences of university students for their reading on-line course-related materials. Her results showed that many learners prefer the paper version of course materials and even those who prefer reading from screen indicated their desire to have the option for printed version due to its portability, reliability, annotation, highlighting and ergonomic features. Another research on university students was conducted by Liu [6] in order to figure out their perception, preferences and use of print or electronic resources. As a result of this study, he concluded that learners "...desire a hybrid information environment" considering that "digital libraries and traditional libraries have their unique advantages and limitations" [6]. Thus, although students benefit from digital reading resources, they still require having traditional libraries for their specific advantages.

Tseng [7] studied the difficulties with reading text on the web. According to his findings, students' complaints about reading from the screen are described in five types; 1) 
eye-strain and eyes-blurred, 2) bright background color, 3) easy to skip lines, 4) small font size and 5) other reasons like paper habits, radiation from the screen etc. These kinds of complaints guide research-development departments of technology companies to improve their products with digital screens, e.g., paper like screens provide lusterless vision in order to protect eyes and let students spend more time with their reading. In another study, Son [8] compared paper-based format with two different screen format as hypertext and non-hypertext format. He concluded that due to ease of working on the text, they felt more motivated with hypertext and paper version comparing to non-hypertext version.

Above mentioned studies mostly aim to identify the preferences of people for their reading activity and usually conclude with implications for the development of the technology to read from a digital screen. But some studies directly focus on how to make people read on screen. Mercieca [9] studied the reasons that make people to print, and came out with three main factors: easiness of the paper, highlighting the text, and carrying the paper easily. Such statements constitute the implications and inspirations for further research to improve the screen readability [9].

Another aspect of the preferences might be that whether learners are ready for reading from screen or not. To find an answer to this question, Buzzetto-More, Sweat-Guy and Elobaid [10] studied the awareness of university students about e-books. They found that, although university students are very comfortable about reading from the screen, they hardly have any interaction with e-books. In another study with university students in the UAE, by Alghazo [11], it is concluded that "...web-enhanced instruction is positively viewed by students and it seems to enrich the conventional face-to-face classroom environment."

In summary, it can be concluded from the literature that, people, or more specifically students still have some hesitations towards reading from screen in spite of their positive attitudes towards it. Their choice of reading from a digital screen can be leveraged with the development of screen technologies as well as the prevalence digital resources.

In this study, it is aimed to find out the preferences of university students for reading from a printed text or from a digital screen and if this preference changes from 2008 to 2014. There are many logical reasons to suppose that their preference should have been diverged from paper to screen in 6 years since they own and use vast amount of devices with digital screens nowadays like smart phones that they read and write numerous messages. In addition, the vast variety of social media and similar platforms and the keenness (or addiction) of young people to them led these young people to spend hours with their devices with digital screens. The students of new generation were accepted as "Digital Natives" as it was firstly defined by Prensky [12]. He stated that today's students who were born into information age of computers and the Internet, think and process information fundamentally differently. They are more used to utilize digital devices comparing to their predecessors- "Digital Immigrants".

The gender and the department of the students can be considered as other aspects that affect their preference of paper or screen. Therefore these aspects also analyzed in this study in order to reveal if their preference changes depending on the students' gender or department as well.

\section{Methodology}

The purpose of this research is to determine the preferences of university students for their reading activities when they have the option to read a text from printed paper or from a digital screen. In stimulation of this purpose, the following research questions have guided this study:

A. What is the reading preference of university students, paper or screen?

B. Is there a significant difference between the paper or screen preferences of the students for their readings comparing to 2008 and 2014 ?

C. Is there a significant difference between the paper or screen preferences of the students for their readings according to their gender?

D. Is there a significant difference between the paper or screen preferences of the students for their readings according to their department?

In order to find out the reading from paper or screen preferences of the university students, a questionnaire was conducted to 792 randomly selected students from eight different departments of Faculty of Education at Çukurova University in Turkey. Examples of the questions from the questionnaire are as follows:

A. What is your department?

1. German Language Teaching ( )

2. Science Teaching ( )

3. French Language Teaching ( )

4. English Language Teaching ( )

5. Pre-School Teaching ( )

6. Primary School Teaching ( )

7. Social Science Teaching ( )

8. Psych. Cons. and Guidance ( )

B. What is your gender?

1. Female ( ) 2. Male ( )

C. When you have the choice to read same text from printed paper and digital screen, which one do you prefer?

\section{Digital screen ( ) 2. Printed paper ( )}

TABLE I: DISTRIBUTION OF THE STUDENTS ACCORDING TO THEIR DEPARTMENTS

\begin{tabular}{|l|c|c|}
\hline Departments & f & \% \\
\hline English Language Teaching & 227 & 28.66 \\
\hline French Language Teaching & 34 & 4.29 \\
\hline German Language Teaching & 89 & 11,24 \\
\hline Pre-School Teaching & 202 & 25,51 \\
\hline Primary School Teaching & 100 & 12,63 \\
\hline Psychological Consulting \& Guidance & 68 & 8,59 \\
\hline Science Teaching & 32 & 4,04 \\
\hline Social Science Teaching & 40 & 5,05 \\
\hline Total & 792 & 100 \\
\hline
\end{tabular}

The number of the students was determined in ratio with the number of the students in each department. Since it is a longitudinal study, the questionnaire was first distributed to 400 students in 2008 and then the same questionnaire was distributed to 392 students in 2014 in order to reveal the differences (if any) of students' preferences. Naturally the second group of students was not the same students but a 
newer generation. In Table I, the distribution of the number of students and their departments is presented.

As it is seen in Table I, 227 students from English Language Teaching Department, 34 students from French Language Teaching Department, 89 students from German Language Teaching Department, 202 students from Pre-School Teaching Department, 100 students from Primary School Teaching Department, 68 students from Psychological Consulting \& Guidance Department, 32 students from Science Teaching Department, and 40 students from Social Science Teaching Department participated in the study. In Table II, the gender of the participants is given.

TABLE II: DISTRIBUTION OF THE STUDENTS ACCORDING TO THEIR GENDER

\begin{tabular}{|l|c|c|}
\hline Gender & f & \% \\
\hline Female & 521 & 65,78 \\
\hline Male & 271 & 34,22 \\
\hline Total & 792 & 100 \\
\hline
\end{tabular}

As it is stated in Table II, the questionnaire was conducted to 521 female and 271 male students who are randomly selected with in the faculty of education. The researcher's 19 students who are taking scientific research class assisted to deliver this questionnaire (see Acknowledge). They have conducted the questionnaire face to face with 792 students. The results are analyzed via SPSS Statistics 17.0 software using chi-square analysis.

\section{RESULTS AND DISCUSSION}

\section{A. Printed Paper or Digital Screen Preference}

The first and the most basic question that this study has been seeking to find an answer is the university students' preferences of reading any kind of reading materials (such as textbooks, novels, newspapers, and magazines etc.) from a conventional printed paper or digital screens (-of their laptops, tablets and/or smartphones). Table III shows the percentage of the students' preferences.

TABLE III: DISTRIBUTION OF THE STUDENTS ACCORDING TO THEIR PAPER OR SCREEN PREFERENCES

\begin{tabular}{|l|c|c|}
\hline Preferences & f & \% \\
\hline Paper preferring students & 617 & 77.9 \\
\hline Screen preferring students & 175 & 22.1 \\
\hline
\end{tabular}

As it is indicated in Table III, majority of the students (77.9\%) opts for old-time printed paper whereas; only a small group of them $(22.1 \%)$ prefers digital screens. Therefore it can be inferred that in spite of wide spread use of digital screens, students still prefer the printed paper when they have a choice. It might be not surprising that majority of the students prefer paper instead of digital screen however the size of the difference implies their significant attachment to their paper books and other paper materials.

\section{B. Printed Paper or Digital Screen Preference in 2008 and 2014}

Although students' preference of printed paper instead of digital screen in majority is not a surprising result, the more intriguing question is that if the ratio of this preference had diverged in the last 6 years. Table IV presents the change of numbers and percentage of students from 2008 to 2014.

TABLE IV: THE CHANGE OF THE PAPER OR SCREEN PREFERENCES BETWEEN 2008 AND 2014

\begin{tabular}{|l|c|c|}
\hline BETWEEN 2008 AND 2014 \\
\hline Preferences in 2008 and 2014 & f & \% \\
\hline Paper preference in 2008 & 314 & 78.50 \\
\hline Paper preference in 2014 & 303 & 77.30 \\
\hline Screen preference in 2008 & 86 & 21.50 \\
\hline Screen preference in 2014 & 89 & 22.70 \\
\hline
\end{tabular}

As it can be observed from the Table IV, the students still enjoy using traditional printed papers for their readings. In 2008, the number paper preferring students was 314 and screen preferring students were 86, then in 2014, these numbers are surprisingly very close as 303 paper preferring students and 89 screen preferring students. As a matter of fact at least a slight change was expected in favor of preferring digital screen, however, certain reasons made them attached to conventional printed papers when they have the choice. An extension of this study might be to investigate the reasons underlying their dependence to printed paper for reading although they use devices with digital screens for vast amount of time.

\section{Printed Paper or Digital Screen Preference of Genders}

When approaching the preference of paper or screen the gender might be an important aspect because of the prejudice that men are keener on cutting-edge electronic devices. Therefore it was assumed that male students will constitute the majority of the students that prefer digital screen instead of printed paper. Table $\mathrm{V}$ shows the difference in paper or screen preferences of female and male students.

Although it was expected that male students would prefer screen more than female students, as it is seen in Table 5, it was revealed that there is no significant difference between the preferences of male and female students. Whereas the percentage of male students who prefer paper is $74.5 \%$, it is $79.7 \%$ for male students and likewise the percentage of male students who prefer screen is $25.5 \%$ whereas it is $20.3 \%$ for female students. Therefore it can be concluded that female students also enjoy digital screens as much male students. One of the reasons of that might be the more frequent use of social media by female university students [13]. Thus, they spend more time in front of digital screens and got more familiar with them.

TABLE V: THE PAPER OR SCREEN PREFERENCES OF FEMALE AND MALE STUDENTS

\begin{tabular}{|l|c|c|}
\hline STUDENTS & f & \% \\
\hline Paper preferring female students & 415 & 79.7 \\
\hline Paper preferring male students & 202 & 74.5 \\
\hline Screen preferring female students & 106 & 20.3 \\
\hline Screen preferring male students & 69 & 25.5 \\
\hline
\end{tabular}

$\chi^{2}=2.710 s d=1 P=0.1$

\section{Printed Paper or Digital Screen Preference of Departments}

It was also considered that the departments of the students might play an important role in the preferences of digital screen or printed paper. Table VI shows the departments and their respective number of students that prefer printed paper or digital screen. 
TABLE VI: THE PAPER OR SCREEN PREFERENCES OF STUDENTS FROM EACH DEPARTMENT

\begin{tabular}{|l|c|c|c|c|}
\hline & \multicolumn{2}{|c|}{ Paper } & \multicolumn{2}{c|}{ Screen } \\
\hline Departments & f & \% & f & \% \\
\hline English Language Teaching & 181 & 79.7 & 46 & 20.3 \\
\hline French Language Teaching & 26 & 76.47 & 8 & 23.52 \\
\hline German Language Teaching & 58 & 65.2 & 31 & 34.8 \\
\hline Pre-School Teaching & 159 & 78.7 & 43 & 21.3 \\
\hline Primary School Teaching & 73 & 73.0 & 27 & 27.0 \\
\hline Psyc. Cons. \& Guidance & 54 & 79.4 & 14 & 20.6 \\
\hline Science Teaching & 28 & 87.5 & 4 & 12.5 \\
\hline Social Science Teaching & 34 & 85 & 6 & 15 \\
\hline$\chi^{2}=15.382$ sd=7 $P=0.31$ & & & & \\
\end{tabular}

As it is implied in the Table VI, there were not significant differences between the preferences of the students from different departments except the language teaching departments. The students of these departments choose to read from a digital screen more than the students of other departments. One reason might be that they have the advantage of knowing one (or more) foreign language to access to the on-line content of the Internet. Therefore they spent more time with digital screens and again got used to read the content from a digital screen.

\section{CONCLUSION}

The results of this study imply that the majority of the students still opt for performing their reading activities through printed papers instead of digital screens. There might be many reasons underlying this choice and it should be illuminating to study these reasons to guide those who are working on designing digital reading mediums.

It is also indicated in the study that the time frame of 6 years have not changed the preferences of the students. One reason might be that they do not have sufficient meaningful/academic interaction with their devices with digital screens. In fact they mostly use them to access social media which requires writing and reading of very limited words (even just 140 characters). Besides, in the scope of a large-scale project to include more technological material in the education system, the Turkish Ministry of Education has been delivering tablet PCs with no charge to elementary and high school students. Therefore, this study should be conducted again after 6 more years since a more digitally oriented generation is on the way owing to those tablet PCs. The university students of 2020 might be the generation that have studied their course books through their tablet PCs and might have had less interaction with printed paper.

Another implication of this study is that there is an explicit equality of female and male students' preference of reading from a digital screen or printed paper. Therefore, it can be suggested that designers of digital reading materials should at least equally (if not more) take into account of specific preferences of female students when they are reading from a digital screen. For instance they may prefer a better facility to take notes, underline or highlight when they are reading from a digital device.

Consequently, majority university students still prefer to read from printed paper instead of digital screen and this preference have not changed when compared to six years ago and today. In addition, gender is not a distinctive factor in this preference; both female and male students have very close percentages in their choices. The students of language teaching departments prefer reading from digital screen more than the other students.

\section{ACKNOWLEDGMENT}

Z. Kazanci thanks his students: Abdulkadir, Abdullah, Aslıhan, Cem, Cemre, Damla, Esra, Fatma, Fidan, Hilmi, Kübra, Nil, Pelinsu, Saniye, Sefa, Yağmur, Yasemin, Yelda and Zafer for their great effort to find and interview 800 students. Without their contribution I could not achieve that many students who are vital to increase the quality of this study.

\section{REFERENCES}

[1] S. H. Kurniawan and P. Zaphiris, "Reading online or on Paper: Which is faster?" Abridged Proceedings of the 9th International Conference on Human Computer Interaction, pp. 220-222, August 5-10, 2001.

[2] S. A. Auman, "High school students' decisions to read print or electronic text: Learning outcomes and preferences," M.S. thesis, Faculty of the School of Information and Library Science, University of North Carolina, Chapel Hill, North Carolina, USA, 2002.

[3] A. Mangen, B. R. Walgermo, and K. Brønnick, "Reading linear texts on paper versus computer screen: Effects on reading comprehension," International Journal of Educational Research, vol. 58, pp. 61-68, 2013.

[4] R. Ackerman and T. Lauterman, "Taking reading comprehension exams on screen or on paper? A metacognitive analysis of learning texts under time pressure," Computers in Human Behavior, vol. 28, no. 5, pp. 1816-1828, 2012.

[5] C. Spencer, "Research on learners' preferences for reading from a printed text or from a computer screen," Journal of Distance Education, vol. 21, no. 1, pp. 33-50, Spring, 2006.

[6] Z. Liu, "Print vs. electronic resources: A study of user perceptions, preferences, and use," Information Processing \& Management, vol. 42, issue 2, pp. 583-592, March 2006.

[7] M. C. Tseng. (2008). The Difficulties That EFL Learners have with Reading Text on the Web. TESL Journal. [Online]. 14(2). Available: http://iteslj.org/Articles/Tseng-TextOnTheWeb.html

[8] J. B. Son, "A hypertext approach to foreign language reading: Student attitudes and perceptions," Australian Review of Applied Linguistics, vol. 17, pp. 91-110, 2003.

[9] P. Mercieca, "E-book acceptance: what will make users read on screen?" Victorian Association for Library Automation, pp. 1-11, 2004.

[10] N. Buzzetto-More, G. Retta, and E. Muna, "Reading in a digital age: E-books are students ready for this learning object?" Interdisciplinary Journal of E-Learning and Learning Objects, vol. 3, issue 1, pp. 239-250, 2007.

[11] I. M. Alghazo, "Student attitudes toward web-enhanced instruction in an educational technology course," College Student Journal, vol. 40 no. 3, 2006.

[12] M. Prensky, "Digital natives, digital immigrants," On the Horizon, vol. 9, pp. 1-6, 2001.

[13] S. G. Mazman and Y. Koçak-Usluel, "Gender differences in using social networks," Turkish Online Journal of Educational Technology-TOJET, vol. 10, issue 2, pp. 133-139, 2011.

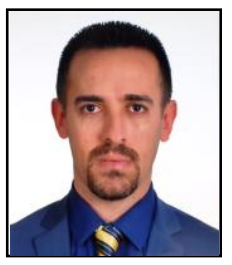

Zekeriya Kazanci was born in Kahramanmaras, Turkey in 1977. He got his bachelor degree in English language teaching at Çukurova University in 2001 in Adana/Turkey and then since he wanted to study interdisciplinary subjects he got his master degree in computer education and instructional technologies from the same university in 2003. Now he is working on his $\mathrm{PhD}$ dissertation in the same department. He usually concentrates his studies on the integration of educational technologies into language teaching.

He has accomplished his military service in 2006 in Turkish General Staff as a liaison officer. He worked as an English teacher from 2001 to 2005. Since 2005 he has been working as an instructor at Çukurova University, Computer Education and Instructional Technologies Department in Adana / Turkey. One of his study fields is the utilization of computer games to teach English vocabulary. Currently he is working on mobile apps to enhance vocabulary teaching. 